\title{
Echocardiographic Guidance During Placement of the Buttoned Double-Disk Device for Atrial Septal Defect Closure
}

\author{
L. LUANN MINICH, M.D., and A. REBECCA SNIDER, M.D. \\ Department of Pediatrics, C.S. Mott Children's Hospital, University of Michigan Medical Center, \\ Ann Arbor, Michigan
}

The usefulness of two-dimensional and Doppler echocardiography during buttoned double-disk device closure of an atrial septal defect was evaluated in 20 consecutive patients at the time of interventional catheterization. Transesophageal echocardiography was used in 11 patients (ages 5 to 62 years, weights 20 to $91 \mathrm{~kg}$ ). Because of the size of the available transesophageal echo probe, transthoracic echocardiography was used in the remaining 9 patients (ages 4 to 5.5 years, weights 14 to $21 \mathrm{~kg}$ ). In the transesophageal echo group, 1 patient was found to have no atrial septal defect despite a previous diagnosis by transthoracic echocardiography, 3 patients had atrial septal defects too large for closure despite attempts in 2, and 7 patients had transesophageal echo guided device placement. All of these 7 patients had small residual shunts by color Doppler, 2 had unusual arm positions, and 2 had surgical removal of the device due to embolization to the pulmonary artery in 1 and failure to obtain close approximation of the occluder and counteroccluder in 1. In the transthoracic echo group, 2 patients had atrial septal defects too large for closure, 1 patient had no femoral venous access, and 6 patients had transthoracic echo guided device placement. All of these 6 patients had small residual shunts by color Doppler and 3 of the 6 had unusual arm positions. For atrial septal defect sizing, transesophageal echo measurements correlated with catheter balloon size more closely than did transthoracic echo measurements $\left(r^{2}=0.97\right.$ vs 0.86). Echocardiography was particularly useful for sizing the defect in two orthogonal views $(n=18)$, sizing total atrial septal length to determine maximum usable device size $(n=15)$, imaging septal rims $(n=19)$, determining effectiveness of balloon occlusion for sizing ( $n=16)$, placement of occluder and counteroccluder $(n=15)$, detecting residual shunts $(n=15)$, and detecting unusual arm positions with or without new-onset valve regurgitation $(n=5)$. Thus, echocardiographic imaging is an essential component of atrial septal defect closure during cardiac catheterization. (ECHOCARDIOGRAPHY, Volume 10, November 1993)

Doppler ultrasound, two-dimensional echocardiography, atrial septal defect, cardiac catheterization, transesophageal echocardiography

As the number and types of interventional procedures being performed in the cardiac catheterization laboratory have increased, new uses of echocardiographic techniques have evolved. Imaging from both transthoracic and transesophageal approaches has improved the guidance and evaluation of various types of trans-

Address for correspondence and reprints: A. Rebecca Snider, M.D., Duke University Medical Center, Box 3107, Durham, NC 27710. Fax: 919-681-7892. catheter devices for closure of atrial and ventricular septal defects. ${ }^{1,2}$ This study was performed to evaluate the usefulness of two-dimensional and Doppler echocardiography during buttoned double-disk device closure of an atrial septal defect.

Methods
Patients
From March 1990 to April 1991, 20 consecu-
tive patients underwent cardiac catheteriza-


tion for closure of an atrial septal defect with the buttoned double-disk device. Their ages ranged from 4.5 to 62 years and their weights ranged from 14.2 to $91.0 \mathrm{~kg}$. There were $17 \mathrm{fe}$ males and 3 males. All patients were referred with the diagnosis of a secundum atrial septal defect. Three patients had a patent foramen ovale believed to be the source of paradoxical emboli, 4 patients had a small atrial septal defect with minimal or no right ventricular volume overload, and 13 patients had a moderate-to-large atrial septal defect with right ventricular and right atrial volume overload. Associated cardiac defects included mild tricuspid regurgitation in 8 patients, mild mitral regurgitation in 3 , mitral valve prolapse in 3 , left superior vena cava to the coronary sinus in 1 , bicuspid aortic valve in 1 , and repaired coarctation of the aorta in 1.

\section{Interventional Catheterization Procedure}

The techniques used for placement of the buttoned double-disk device have been described in detail previously. ${ }^{3-6}$ In 12 patients, the procedure was performed under general anesthe- sia with endotracheal intubation and, in 8 patients, the procedure was performed under sedation with frequent small doses of ketamine and midazolam. In each patient, right heart catheterization was performed and pressures and oximetry data were obtained in all chambers. An arterial line was placed for blood pressure monitoring throughout the case. A long 8Fr sheath was positioned in the mid-left atrium to deliver the occluder. This sheath was then withdrawn to the mid-right atrium to deliver the counteroccluder. The occluder and counteroccluder were buttoned across the defect and the device was released.

\section{Echocardiographic Evaluation}

Two-dimensional and Doppler echocardiographic examinations were performed on all patients before, during, and after placement of the button device. Transesophageal echocardiography was used in 11 patients ranging in age from 5 to 62 years and in weight from 20 to 91 $\mathrm{kg}$. Because of the size of the available transesophageal probe (5- $\mathrm{MHz}$ imaging frequency, 11-mm tip diameter), transthoracic echocardi-

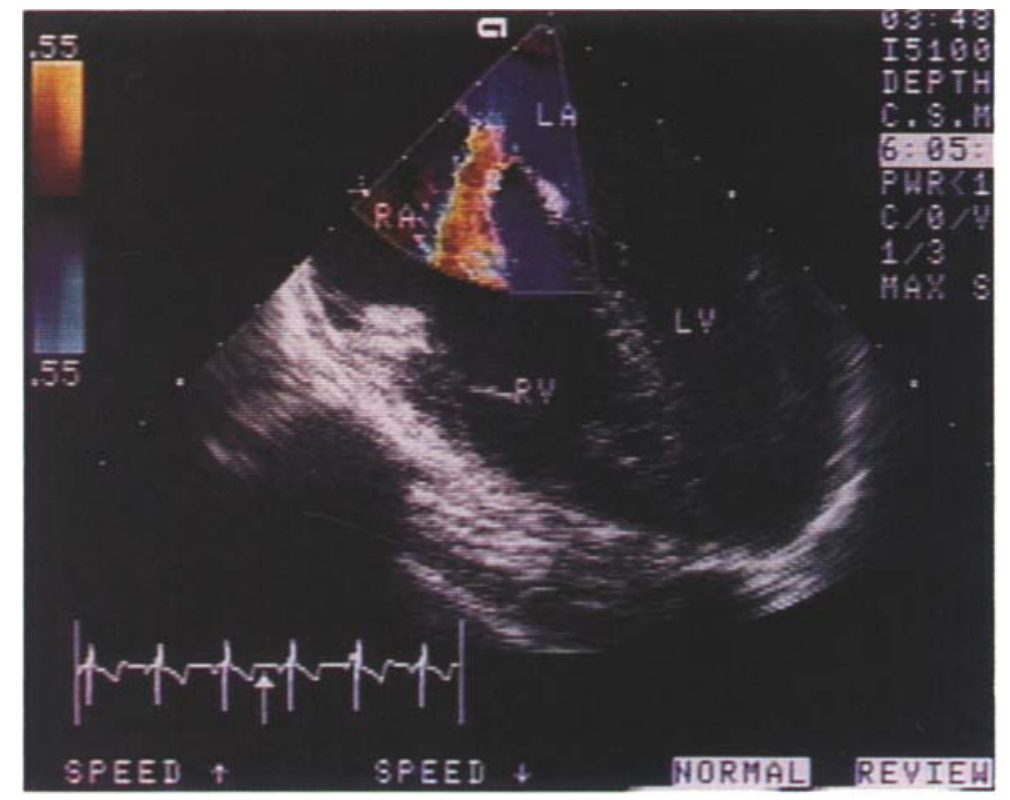

Figure 1. Four-chamber view obtained from the transverse transesophageal echo plane demonstrating left-to-right shunting by color Doppler across a large secundum atrial septal defect. $L A=$ left atrium; $L V=$ left ventricle; $R A=$ right atrium; $R V=$ right ventricle. 


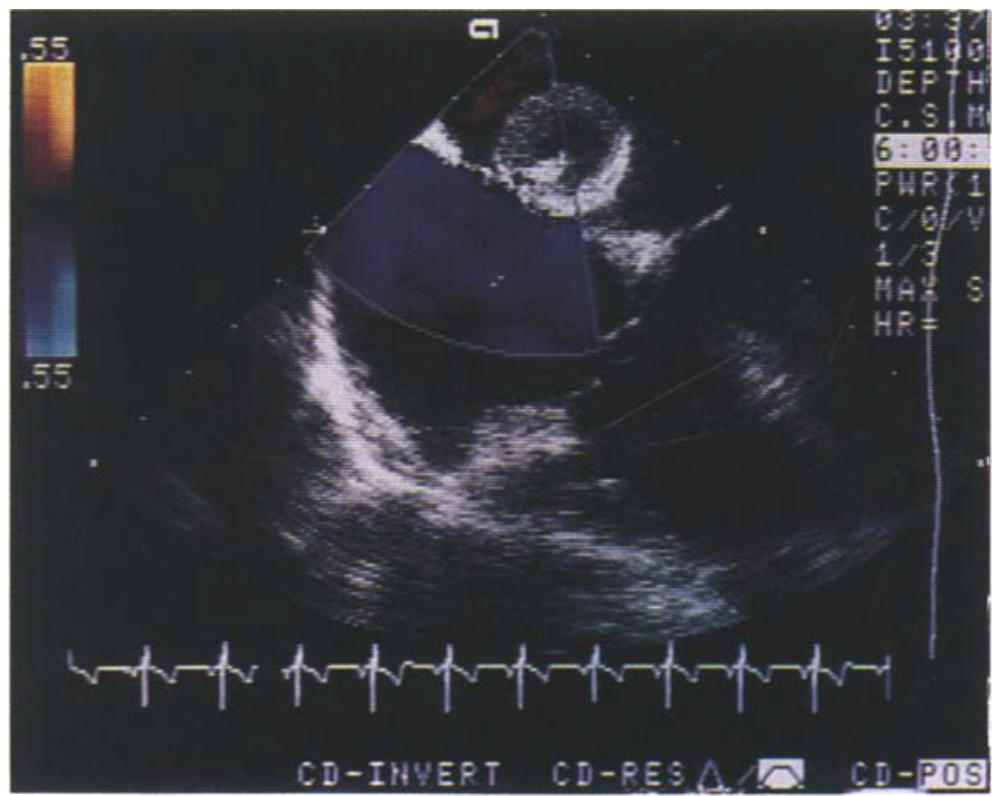

Figure 2. Four-chamber view from the same patient demonstrating balloon sizing of the atrial septal defect under transesophageal echo guidance. The lack of shunting by color Doppler indicates successful balloon occlusion of the defect.

ography from a subcostal or low left parasternal approach was used in the remaining 9 patients who ranged in age from 4 to 5.5 years and in weight from 14 to $21 \mathrm{~kg}$. The type and location of the atrial septal defect were determined (Fig. 1). Measurements of the diameter of the atrial septal defect were made in two orthogonal views using on-line calipers. A similar technique was used to measure the total atrial septal length (used to determine the maximum usable device size). After balloon occlusion of the atrial septal defect as described in previous studies, ${ }^{7,8}$ color Doppler was used to detect any residual shunts and, thus, determine the effectiveness of the occlusion (Fig. 2). Color Doppler mapping techniques were used to detect the direction of shunting, the location of additional atrial septal defects, and residual shunting after device placement.

\section{Results}

Eleven patients were evaluated with transesophageal echocardiography. In this group, 1 patient was found to have no atrial septal defect despite a previous diagnosis by transthoracic imaging. The size of the defect was found to be too large for closure by the maximum usable device in 3 patients despite attempts in 2 . Device placement under transesophageal echo guidance was performed in the remaining $7 \mathrm{pa}$ tients. All of these 7 patients had small residual shunts by color Doppler (Fig. 3). Two of the 7 patients had abnormal arm positions: 1 patient had the occluder protruding into the mitral valve with new-onset mild mitral regurgitation and the counteroccluder protruding into the tricuspid valve (Fig. 4); the other patient had the counteroccluder protruding into the left atrium. Two of the 7 patients required surgical removal of the device: 1 patient had a device that unbuttoned and embolized to the pulmonary artery; the other patient had a device in which the occluder and counteroccluder could not be approximated (faulty device?) causing the flap valve of the foramen ovale to remain in the open position (Fig. 5).

Nine patients were evaluated with transthoracic echocardiography. In this group, 2 patients had atrial septal defects that were too 


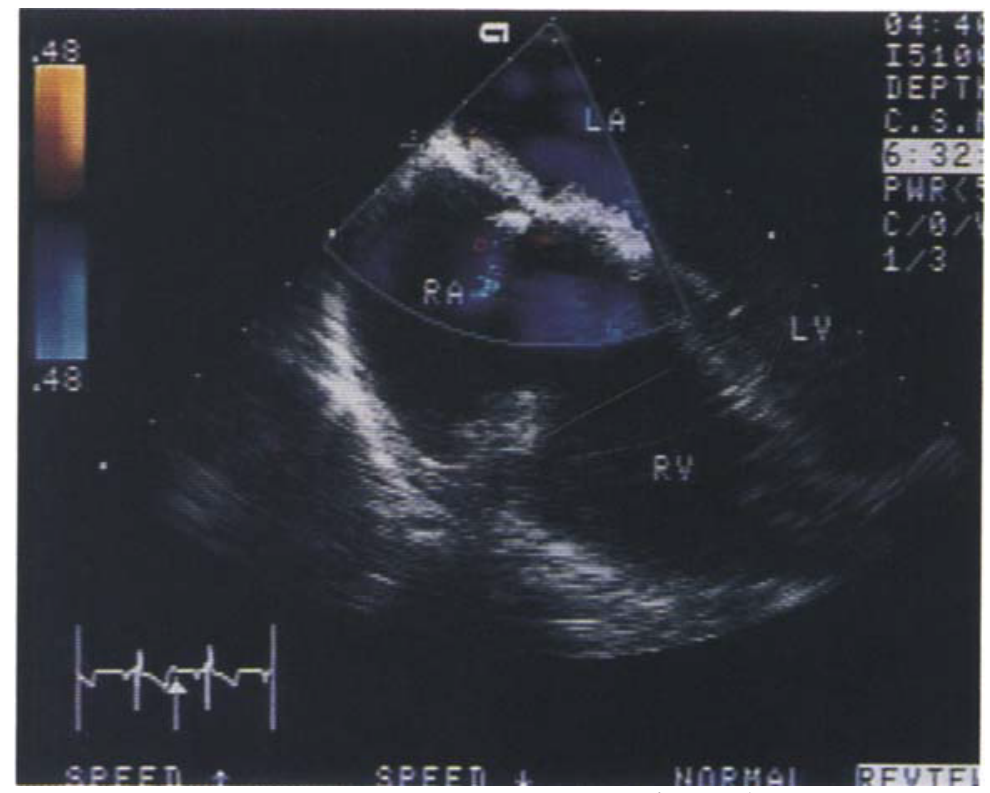

Figure 3. Four-chamber view from the same patient showing the button device in place over the atrial septal defect with a small residual shunt by color Doppler. $L A=$ left atrium; $L V=$ left ventricle: $R A=$ right atrium; $R V=$ right ventricle.

large for closure with the largest available device. One patient with previous aortic coarctation repair had no femoral venous access. The remaining 6 patients underwent device placement under transthoracic echo guidance. All of these 6 patients had small residual shunts by color Doppler. Three of the 6 patients had ab-

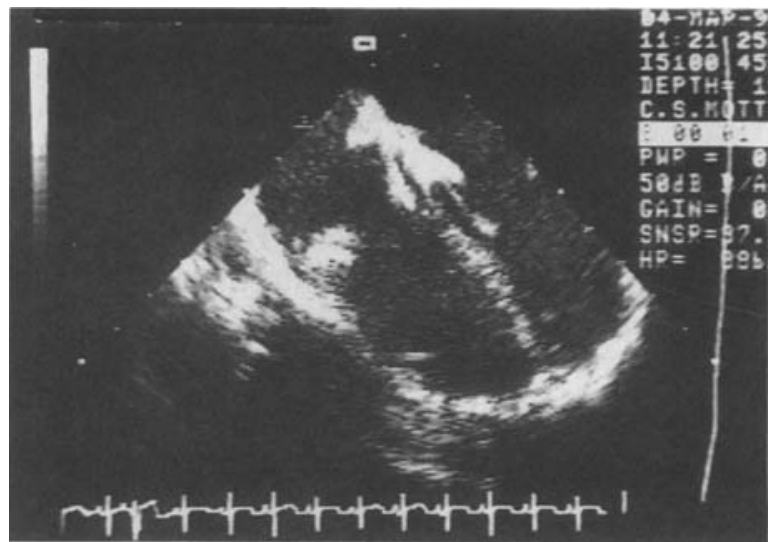

Figures 4. Four-chamber view in the transverse transesophageal echo plane showing the device protruding into the mitral valve and tricuspid valve.

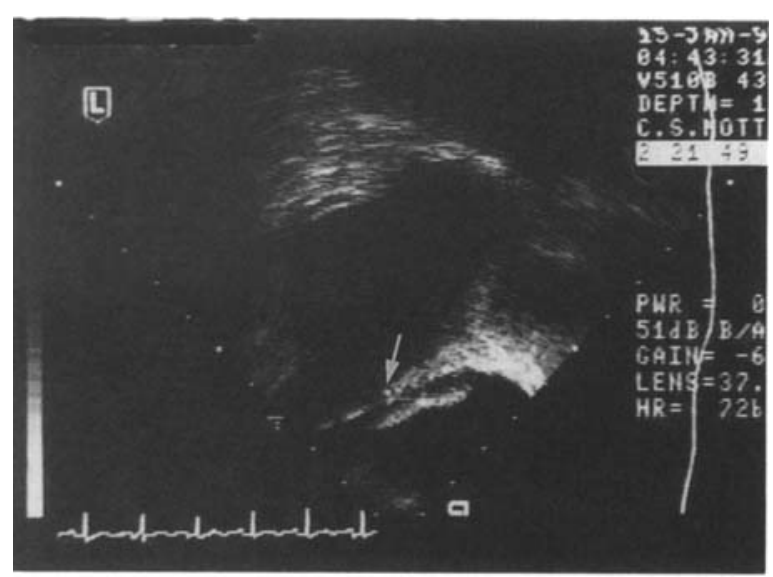

Figure 5. Longitudinal transesophageal echo view showing the occluder in the left atrium widely separated from the counteroccluder and holding the flap valve open. Note the bright echoes arising from the button (arrow) and the echoes arising from the loop of suture material used to perform the buttoning of the two portions of the device. 


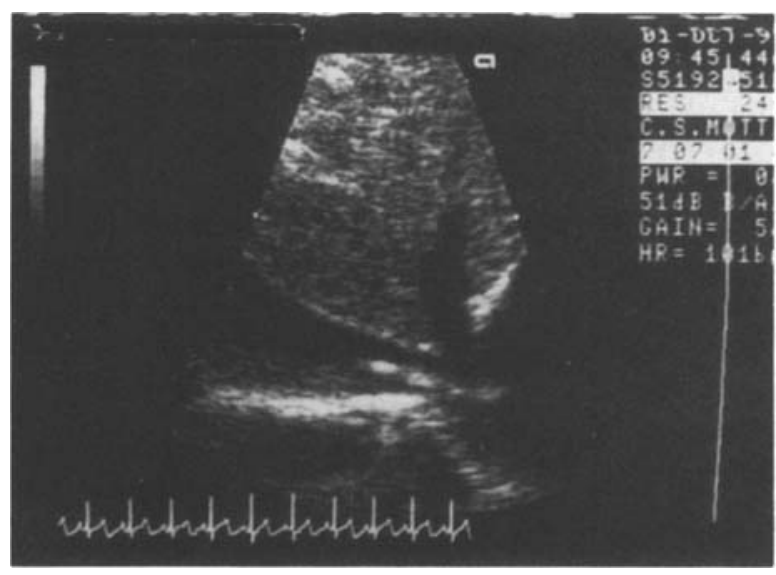

Figure 6. Subcostal long-axis transthoracic echo view showing the tip of the counteroccluder projecting down the inferior vena cava.

normal arm positions: 2 patients had the counteroccluder projecting down the inferior vena cava (Fig. 6); 1 patient had the occluder protruding into the mitral valve with new-onset mild mitral regurgitation and the counteroccluder protruding into the tricuspid valve.

For both the transesophageal echo and transthoracic echo patient groups, the uses of echocardiography during interventional catheterization are summarized in Table I. Also, transesophageal echo measurements of the atrial septal defect diameter correlated with catheterization balloon sizing more closely than did

TABLE I

Uses of Echocardiography

\begin{tabular}{lc}
\hline \multicolumn{1}{c}{ Use } & No. of Pts. \\
\hline (1) Sizing the defect in two orthogonal & 18 \\
views & 15 \\
(2) Sizing total septal length to determine & \\
maximum usable device size & 19 \\
(3) Imaging septal rims & 16 \\
(4) Determining the effectiveness of & 15 \\
balloon occlusion & 15 \\
(5) Occluder and counteroccluder & 5 \\
(6) Residual shunts & 2 \\
(7) Detecting unusual arm positions & \\
(8) Detecting new-onset valve & \\
regurgitation &
\end{tabular}

transthoracic echo measurements $\left(r^{2}=0.97\right.$ vs 0.86 ).

\section{Discussion}

Two-dimensional and Doppler echocardiography have been used routinely to evaluate the size, location, and anatomy of the atrial septal defect. In older patients with larger body surface areas, transthoracic imaging is often inadequate, decreasing the sensitivity and specificity of the examination. ${ }^{9,10}$ Newer transesophageal echo techniques that provide posterior windows for clear imaging of the atrial septum and surrounding structures have overcome this problem. ${ }^{1-16}$ In this study, echocardiography played an important role in the evaluation of patients undergoing atrial septal defect closure with the transcatheter double-disk device (Table I).

Measurements of the atrial septal defect were made in two orthogonal views to determine the size of the device needed to occlude the defect. To determine the maximal usable device size, measurements of the total atrial septal length were also made. In addition to these measurements, balloon sizing of the atrial septal defect was performed using color flow Doppler to insure the effectiveness of the occlusion. After the defect size was determined, the location of the closure device and its components were monitored continuously by systematically sweeping the transducer to scan the atrial septum and surrounding structures in multiple planes. As the arms of the device were not all in the same plane, scanning in multiple planes was essential. The button of the device was visualized and its location during fastening of the occluder and counteroccluder was monitored. The positions of the arms of the device were evaluated with respect to the rims of the atrial septal defect, pulmonary and systemic venous inflows, and tricuspid or mitral valve funnels. Color Doppler was used to evaluate any new-onset valve regurgitation or the development of venous obstruction due to unusual arm positioning. The presence of residual atrial shunting was readily determined with Doppler color flow mapping. Echocardiography was useful in determining if the device was unstable, 
mobile, or dislodged after placement. Progression or resolution of shunting, valve regurgitation, or venous obstruction was readily assessed with serial follow-up Doppler echocardiographic examinations. Since the long-term effects of these devices are unknown, serial echocardiographic studies would also provide additional information regarding thrombus formation or embolization.

Echocardiography is useful for sizing the atrial septal defect in two orthogonal views, sizing the total septal length to determine maximum usable device size, imaging septal rims, determining effectiveness of balloon occlusion for sizing, placement and buttoning of the occluder and counteroccluder, detecting residual shunts, and locating abnormal arm positions with or without new-onset valve regurgitation. Thus, echocardiographic imaging is an essential component of atrial septal defect closure with a catheter device.

\section{References}

1. Hellenbrand WE, Fahey JT, McGowan FX, et al: Transesophageal echocardiographic guidance of transeatheter closure of atrial septal defect. Am J Cardiol 1990;66:207-213.

2. Stumper O, Witsenburg M, Sutherland GR, et al: Transesophageal echocardiographic monitoring of interventional cardiac catheterization in children. $J$ Am Coll Cardiol 1991;18: 1506-1514.

3. Sideris EB, Sideris SE, Fowlkes JP, et al: Transvenous atrial septal defect occlusion in piglets with a "buttoned" double-disk device. Circulation 1990;81:312-318.

4. Sideris EB, Sideris SE, Thanopoulos BD, et al: Transvenous atrial septal defect occlusion by the buttoned device. Am J Cardiol 1990;66: 1524-1526.

5. Rao PS, Wilson AD, Levy JM, et al: Role of "buttoned" double-disc device in the management of atrial septal defects. Am J Cardiol 1992;123: 191-200.
6. Rao PD, Wilson AD, Chopra PS: Transcatheter closure of atrial septal defect by "buttoned" devices. Am J Cardiol 1992;69:1056-1061.

7. King TD, Thompson SL, Mills NL: Measurement of atrial septal defect during cardiac catheterization: Experimental and clinical results. Am J Cardiol 1978;41:537-542.

8. Rao PS, Langhough R: Relationship of echocardiographic, shunt flow, and angiographic size to the stretched diameter of the atrial septal defect. Am Heart J 1991;122:505-508.

9. Shub C, Dimopoulos IN, Seward JB, et al: Sensitivity of two-dimensional echocardiography in the direct visualization of atrial septal defect utilizing the subcostal approach: Experience with 154 patients. $J$ Am Coll Cardiol 1983;2: 127-135.

10. Khandheria BK, Shub C, Tajik AJ, et al: Utility of color flow imaging for visualizing shunt flow in atrial septal defect. Int $J$ Cardiol 1989;23: 91-98.

11. Mehta RH, Helmcke F, Nanda NC, et al: Transesophageal Doppler color flow mapping assessment of atrial septal defect. J Am Coll Cardiol 1990;16:1010-1016.

12. Pearson AC, Labovitz AJ, Tatineni S, et al: Superiority of transesophageal echocardiography in detecting cardiac source of embolism in patients with cerebral ischemia of uncertain etiology. J Am Coll Cardiol 1991;17:66-72.

13. Kronzon I, Tunick PA, Freedberg RS, et al: Transesophageal echocardiography is superior to transthoracic echocardiography in the diagnosis of sinus venosus atrial septal defect. $J \mathrm{Am}$ Coll Cardiol 1991;17:537-542.

14. Stumper O, Kaulitz R, Elzenga NJ, et al: The value of transesophageal echocardiography in children with congenital heart disease. $J A \mathrm{Am}$ Soc Echocardiogr 1991;4:164-176.

15. Ritter SB: Transesophageal real-time echocardiography in infants and children with congenital heart disease. J Am Coll Cardiol 1991;18: 569-580.

16. Pearson AC, Nagelhout D, Castello $R$, et al: Atrial septal aneurysm and stroke: A transesophageal echocardiographic study. J Am Coll Cardiol 1991;18:1223-1229. 